\title{
Structure Formation Process of Hydrated Portland Cement Compositions: Nanoscale Level Control
}

\author{
Guryanov A.M., Korenkova S.F., Sidorenko Yu.V. \\ Samara State Technical University, Institute of Architecture and Civil Engineering \\ Address: Molodogvardeyskaya St., 194, Samara, 443001, Russia
}

\begin{abstract}
Durability of cement-like construction materials, as well as durability of cement stone, depends on their humidity resistance, frost resistance, corrosion resistance. All of these properties depend not only on the composition of the original clinker, but also on structural organization at micro-and nanoscale level of hydrated portland cement compositions. In this research the authors used the method of small-angle neutron scattering to define structural parameters of hydrated portland cement compositions on nanoscale level, distribution of calcium hydrate silicate nanoparticles in size, medium nanoparticles radius, fractal dimension. It is shown, that introduction of modifying nanoadditives into portland cement compositions affects structural parameters of a cement stone. The following nanoadditives were used: of artificial (alpha aluminium oxide, gamma aluminum oxide) and of anthropogenic (carbonate and alumo-alkaline sludges) origin, as well as integrated nanoadditives containing surfactants. The change in structural parameters of portland cement compositions with nanoadditives in the process of hydration is investigated. It is shown that use of nanoadditives allows to control the process of forming the structure of hydrated portland cement composition on the nanoscale level, directly affect the values of structural parameters and, as a result, modify properties of cement stone.
\end{abstract}

Keywords: Portland cement, cement composition, nano additives, surfactants, small-angle neutron scattering, fractal dimension.

\section{INTRODUCTION}

Hydration of cement clinker leads to formation of complex gel-like frame of calcium hydrate silicate particles (C-S-H) [1, 2]. Parameters describing C-S-H particles structure and as well as parameters of the cement matrix itself, affect the properties of cement stone which is formated during the process [3, 4]. Strength and durability (which are closely connected with water resistance, frost resistance, corrosion resistance and other properties of cement stone) are influenced by shape and size distribution of C-S-H nanoparticles, by the ratio of free and bound water, by the presence of pores and their distribution in shape and size, that is, structural parameters of the material at micro-and nanoscales [5-7].

Certain specified properties of cement-like construction materials can be obtained by using different additives (fillers, modifiers) of artificial (e.g., carbon materials, other fine and ultra-fine powders) and of man-made (slimes, slags etc.) origin [5-7]. Additives affect structure formation in the process of initial hydration of portland cement clinker, and thus, affect operational properties of obtained materials [8-11]. This is especially evident when there are nanodispersed components present in cement compositions of additives. According to characteristic features of their influence on the properties of resulting building materials, such additives can be described as nanoadditives or nanomaterials.

From the point of view of their effects, raw sludges, in their turn, can be referred to as filling additives (e.g., carbonate slimes) or as structureforming additives (for example, alumoalkaline sludges). Sludges are formed as a result of processes of chemical reactions, dispersing and mixing, as well as adsorption, coagulation and sedimentation of particulate matters from oversaturated sewage solutions while their cleaning or water softening in industrial plants of metal industry, oil refining factories, thermal power plants. Slimes are a suspension, characterized by structure stability, homogeneity and consistency of composition [12]. Compliance with conditions of sludges by sol-gel technology, as well as the existence of nanodispersed components allows to refer them to nanotechnogenic raw materials.

In this paper, the authors used a method of smallangle neutron scattering (SANS), carried out a study of structures formation at the nanoscale of hydrated portland cement compositions, modified with nanoadditives of both artificial (Alpha aluminium 
oxide nanoparticles, gamma alumina) and of manmade (carbonate and alumoalcaline sludges), and identified structural parameters of portland cement compositions. The influence of surfactants on structural parameters was also studied. It was proved that a combination of nanoadditives of different focus makes it possible to control the process of structures formation (structural parameters) of portland cement compositions during the process of hydration.

\section{II.EXPERIMENTAL METHODS}

Hydration of cement clinker leads to formation of complex gel-like frame of calcium hydrate silicate particles (C-S-H) [1, 2]. Parameters describing C-S-H particles structure and as well as parameters of the cement matrix itself, affect the properties of cement stone which is formated during the process [3, 4]. Strength and durability (which are closely connected with water resistance, frost resistance, corrosion resistance and other properties of cement stone) are influenced by shape and size distribution of C-S-H nanoparticles, by the ratio of free and bound water, by the presence of pores and their distribution in shape and size, that is, structural parameters of the material at micro-and nanoscales [5-7].

It is possible to use a method of small-angle neutron scattering (SANS) to determine parameters of over-atomic structure of samples of portland cement compositions applicable to distances from $1 \mathrm{~nm}$ to $100 \mathrm{~nm}$ [13]. This method is quite applicable to the investigation of nanoobjects of different physical nature because of the dependence of the intensity of SANS from scattering ability of inhomogeneities in the structure of substances and contrast at the borders of phase interface. The method of small-angle neutron scattering was firstly introduced in 1938 by A. Guinier in his works on over-atomic metallic structure. In 1950-ies this method was further developed in the works by G. Porod, O. Kratky and V. Luzzati. Now SANS is successfully used for research at the nanoscale of various materials, including the definition of structural parameters of hydrated cement compositions [14-16].

The intensity of SANS $I(q)$ depends on the transmitted neutron pulse.

$$
q=\frac{4 \pi}{\lambda} \sin \frac{\theta}{2}
$$

where $\theta$ is the scattering angle which carries information about over-atomic structure of scattering particles.

When performing the condition $q R_{c}<1$ (Guinier regime) small angle scattering intensity $I(q)$ is defined by a characteristic particles size and shape of scattering particles or their inhomogeneities:

$$
I(q)=I(0) \exp \left(-\frac{R_{g}^{2}}{3}\right)
$$

where $R_{g}$ is the radius of particles gyration. From experimental data on low-angle scattering in Guinier regime it is possible to estimate the radius of gyration $R_{g}$ of the particles and their characteristic size $R_{c}$.

When performing the condition $q R_{c}>1$ (Porod regime) for small angle scattering intensity there exists power-law dependence from transmitted neutron pulse.

$$
I(q) \propto q^{-n} .
$$

Deviation of exponent $n$ from Porod asymptotics $(n=4)$ points to the fractal properties of the scattering objects and makes it possible to determine their fractal dimension. In the case of bulk or mass fractals the exponent coincides with the fractal dimension $n=D_{V}$ and takes a value from the interval $1<D_{V}<3$. In the case of scattering objects with fractal surface, fractal dimension equals $D_{S}=6-n$ and takes a value from the interval $2<D_{S}<3$. Accordingly, the exponent lies in the interval $3<n<4$.

Thus, according to the slope of straight-line portions of SANS dependencies, built in a double logarithmic scale, it is possible to determine whether the scattering objects belong to a specific type of fractal (volumetric or surface) and their fractal dimension [17-19].

According to data on low-angle scattering for polydisperse systems, it is possible to restore distribution functions of scattering objects for distances $G(R)$, on the basis of spectra of pair correlations $\gamma(R)$, obtained by Fourier transforms of data for cross sections. These functions are related to the forms of particles and describe quantitatively a set of line segments connecting the elements of the volume of particles, and also depend on the distribution of inhomogeneities within particles. Distribution function by distances $G(R)$ can be presented as follows:

$$
G(R)=R^{2} \gamma(R)=\frac{1}{2 \pi^{2}} R^{2} \int \frac{d \sigma(q)}{d \Omega} \frac{\sin (q R)}{q R} q^{2} d q .
$$

The function $G(R)$ shows whether particles of the radius $R$ exisr in the test material.

Processing of SANS experimental data is implemented by use software complex ATSAS 2.8.0 [20, 21].

\section{EXPERIMENTS}

Spectra intensities SANS from samples of cement compositions were measured in Petersburg nuclear physics Institute (the town of Gatchina) with a diffractometer "Membrane-2" installed on the WWR- 
$M$ reactor [22]. Wavelength of neutrons was equal to $\lambda=0.3 \mathrm{~nm}$ with linewidth $\Delta \lambda \lambda=0,25$. Range of registered elastic transferred neutron pulses $q$ was ranging from $0.03 \mathrm{~nm}^{-1}$ to $0.8 \mathrm{~nm}^{-1}$. Scattered specimens of neutrons were recorded in the range of angles $\theta= \pm 0.017 \mathrm{rad}$. The detector consisted of forty one ${ }^{3}$ ne-counter. The intensity of the beam on the sample was measured while using two counters (monitors), installed in front of the model above and below the axis of the beam of neutrons.

Samples of hydrated portland cement compositions were placed in a target device representing the cavity in a cadmium plate. The volume of the cavity was $0.52 \mathrm{~cm}^{3}$. The thickness of the sample was equal to the cadmium plate thickness $d_{\mathrm{S}}=2 \mathrm{~mm}$. With this thickness of the samples, values of transmission coefficient (transmission) of the beam of neutrons were $T=0.4-0.9$.

The results obtained from the experiment data were standardized with monitors readings and transmission values. Background subtraction was carried out, as well as the effect of neutrons thich had passed through the sample without scattering. The obtained distributions of scattering intensities $I_{\mathrm{S}}(q)$ were then standardized with scattering intensities obtained under the same conditions $I_{\mathrm{ST}}(q)$ from the standard sample, which was a light water layer of й $d_{\mathrm{ST}}=1 \mathrm{~mm}$ thickness Differential cross-sections of portland cement compositions samples scatterings per $1 \mathrm{~cm}^{3}$ of the volume of the sample in absolute units was calculated by the formula

$$
\frac{d \sigma(q)}{d \Omega}=\frac{I_{S}(q)}{I_{S T}(q)} \frac{d_{S T}}{d_{S}} \frac{d \sigma_{S T}}{d \Omega} .
$$

From the obtained cross sections of neutrons scattering, by means of Fourier transformation (4) we restored the distribution of scattering objects in the approximation of homogeneous areas.

When fitting experimental data, the maximum radius of scattering objects was ranged from 50 to $100 \mathrm{~nm}$. When the maximum radius was equal to 50 $\mathrm{nm}$, the points corresponding to minimal neutron pulses fell through. This part of the test is not described and taken into account. When the maximum radius was equal to $100 \mathrm{~nm}$, the points corresponding to maximum neutron pulses fell through. This part of the test is not described and taken into account either. The general description of scattering data was quite correct, if the maximum size of the dispersal areas was about $80 \mathrm{~nm}$. The average radius of the scattering objects for tested samples of cement compositions was ranging from $30 \mathrm{~nm}$ to 65 $\mathrm{nm}$.

Samples of cement compositions were made on the basis of portland cement D0-500 with no additives. During the process of of Portland cement hydration, nanoadditives in the amount of $2,5 \div 5 \%$ were put into it. They were nanopowders $\alpha-\mathrm{Al}_{2} \mathrm{O}_{3}$ и $\gamma-\mathrm{Al}_{2} \mathrm{O}_{3}$, , carbonate or alumoalkaline sludge, as well as about $0.5 \%$ of surface acting agents. Nanopowder $\alpha-\mathrm{Al}_{2} \mathrm{O}_{3}$ was characterized by an average particle size of $80 \mathrm{~nm}$ with a specific surface area of not less than $10 \mathrm{~m}^{2} / \mathrm{g}$. Nanopowder $\gamma-\mathrm{Al}_{2} \mathrm{O}_{3}$ had average particle size of $20 \mathrm{~nm}$ and specific surface area of not less than $160 \mathrm{~m}^{2} / \mathrm{g}$. The composition of the sludge used in this work is given in Table 1. As surface acting agents superplasticizing agent of brand C-3 was used.

Table I

Mineral composition of raw sludges

\begin{tabular}{|l|c|c|c|c|c|}
\hline $\begin{array}{l}\text { A sample of raw } \\
\text { sludge }\end{array}$ & $\begin{array}{c}\mathrm{Al}_{2} \mathrm{O}_{3} \\
{[\%]}\end{array}$ & $\begin{array}{c}\mathrm{CaO} \\
{[\%]}\end{array}$ & $\begin{array}{c}\mathrm{MgO} \\
{[\%]}\end{array}$ & $\begin{array}{c}\mathrm{Fe}_{2} \mathrm{O}_{3} \\
{[\%]}\end{array}$ & $\begin{array}{c}\mathrm{SiO}_{2} \\
{[\%]}\end{array}$ \\
\hline Carbonate & 10 & 43 & 6 & 2 & $\begin{array}{c}\mathrm{Losses} \text { at } \\
\text { steam curing } \\
{[\%]}\end{array}$ \\
\hline Alumoalkaline & 52 & 2 & 2 & 2 & 4 \\
\hline
\end{tabular}

Water/cement ratio was ranged from 0.27 to 0.30 . When raw sludges and surface acting agents were added, water/cement ratio decreased to values of 0.18-0.24.

Periodically measurement of neutron scattering intensities of manufactured samples was done. According to the charts of neutron scattering intensities the following calculations were performed: According to formula (2) the average radii of scattering objects were calculated; according to formula (3) -fractal dimensions; according to formula (4) - differential cross-sections of scattering; according to formula (5) - distribution function of scattering objects by distances.

Calculated structural parameters of samples were compared. The time interval of measurement cycles was 28 days.

\section{DISCUSSION AND RESULTS}

Table 2 shows the composition of the samples of tested cement compositions. For all samples we observed power dependence of the scattering intensity from the transmitted neutron pulse. As an example, Figure 1 presents graphs of the neutron scattering intensities of three samples after 28 days from the start of hydration. Sample 1 is made portland cement D0-500 with no additives. Sample 8 is a cement composition with $5 \%$ of $\gamma-\mathrm{Al}_{2} \mathrm{O}_{3}$ additive. Sample 10 is a cement composition with $5 \%$ of $\alpha$ $\mathrm{Al}_{2} \mathrm{O}_{3}$ additive.

Figure 2 shows graphs of calculated functions of scattering objects distribution by distances for samples 8 and 10 .

Characteristics of the tested samples of portland cement compositions, calculated values of fractal 
dimensions $D_{S}$ and average particles size $R_{c}$ are shown in Table 2.

In sample 2 and 3, 4 and 5, 6 and 7 (as shown in Table 2) added sludges had similar chemical compositions. Average particle size $R_{c}$ was calculated on the 28th day aftercement compositions gauging.

Table 2 demonstrates that nanoadditives in portland cement compositions change structural parameters of materials at the nanoscale. All nanoadditives in the range of distances up to $80 \mathrm{~nm}$ reduce the average size of the scattering objects. In the specified range of distances, scattering of neutrons occurs on fractal surfaces. Increase of the fractal dimensions in the process of hydration points to the strength increase in the surface area in the process of portland cement hydration of calcium silicate particles. Influence of structural parameters of nanoadditives is connected not only with nanodimentions of their particles. An important factor here is also the target of the impact on the process of hydration. Carbonate slimes and nanopowders $\alpha$ $\mathrm{Al}_{2} \mathrm{O}_{3}$ и $\gamma-\mathrm{Al}_{2} \mathrm{O}_{3}$ are of low chemical activity. They, most likely, can be attributed to the filling nanoadditives. On the other hand, alumoalkaline sludges as well as complex nanoadditives containing surfactants, or two-component (a mixture of carbon and alumoalkaline sludges) can be attributed to the modifying nanoadditives. They have a greater influence on the structural parameters. Target-specific change of structural parameters of cement compositions by introduction of surfactants is determined by the absorption mechanism of modification of dispersion systems.

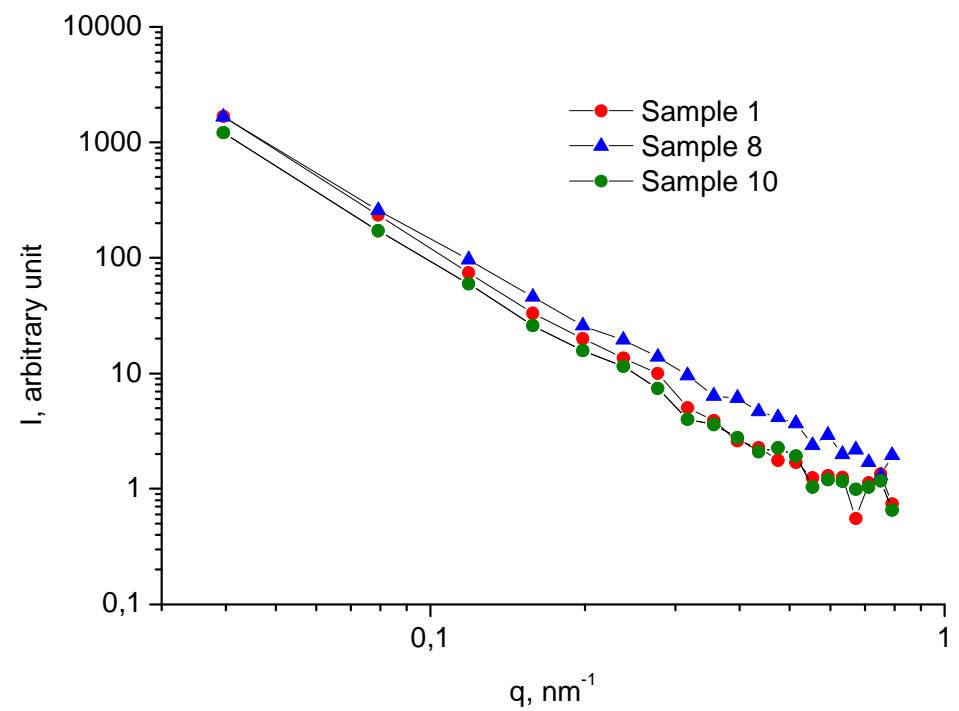

Fig.1. Experimental spectra of SANS intensities of cement compositions samples. Sample 1 - cement without additives; Sample 8 - cement with $\gamma-\mathrm{Al}_{2} \mathrm{O}_{3}$ additive (5\%); Sample 10 - cement with $\alpha-\mathrm{Al}_{2} \mathrm{O}_{3}$ additive (5\%).

Table II

Structural parameters of samples of portland cement compositions

\begin{tabular}{|c|c|c|c|c|c|c|c|}
\hline $\begin{array}{l}\text { Sample } \\
\text { number }\end{array}$ & $\begin{array}{l}\text { Type of additive } \\
\text { (raw sludge)/[\%] }\end{array}$ & $\begin{array}{l}\text { PAV } \\
{[\%]}\end{array}$ & $\begin{array}{c}D_{S} \\
1 \text { day }\end{array}$ & $\begin{array}{c}D_{S} \\
7 \text { days }\end{array}$ & $\begin{array}{c}D_{S} \\
14 \text { days }\end{array}$ & $\begin{array}{c}D_{S}, \\
28 \text { days }\end{array}$ & $\begin{array}{l}R_{c}, \\
\mathrm{~nm}\end{array}$ \\
\hline 1 & - & - & 2.31 & 2.35 & 2.39 & 2.49 & 65 \\
\hline 2 & Carbonate / 5.0 & - & 2.35 & 2.40 & 2.52 & 2.55 & 60 \\
\hline 3 & Carbonate / 5.0 & 0.25 & 2.37 & 2.41 & 2.55 & 2.58 & 45 \\
\hline 4 & Alumoalkaline / 4,5 & - & 2.44 & 2.50 & 2.62 & 2.76 & 42 \\
\hline 5 & Alumoalkaline / 4,5 & 0.25 & 2.48 & 2.58 & 2.71 & 2.85 & 40 \\
\hline 6 & $\begin{array}{c}\text { Carbonate / } 3.0+ \\
\text { Alumoalkaline / } 3.0\end{array}$ & - & 2.40 & 2.48 & 2.56 & 2.62 & 52 \\
\hline 7 & $\begin{array}{c}\text { Carbonate / } 3.0+ \\
\text { Alumoalkaline / } 3.0\end{array}$ & 0.25 & 2.41 & 2.52 & 2.58 & 2.68 & 43 \\
\hline 8 & $\gamma-\mathrm{Al}_{2} \mathrm{O}_{3} / 5,0$ & - & 2.40 & 2.50 & 2.58 & 2.60 & 48 \\
\hline 9 & $\gamma-\mathrm{Al}_{2} \mathrm{O}_{3} / 5,0$ & 0.25 & 2.41 & 2.54 & 2 & 2.68 & 44 \\
\hline 10 & $\alpha-\mathrm{Al}_{2} \mathrm{O}_{3} / 5.0$ & - & 2.30 & 2.35 & 2.36 & 2.48 & 52 \\
\hline 11 & $\alpha-\mathrm{Al}_{2} \mathrm{O}_{3} / 5.0$ & 0.25 & 2.38 & 2.40 & 2.41 & 2.52 & 50 \\
\hline
\end{tabular}




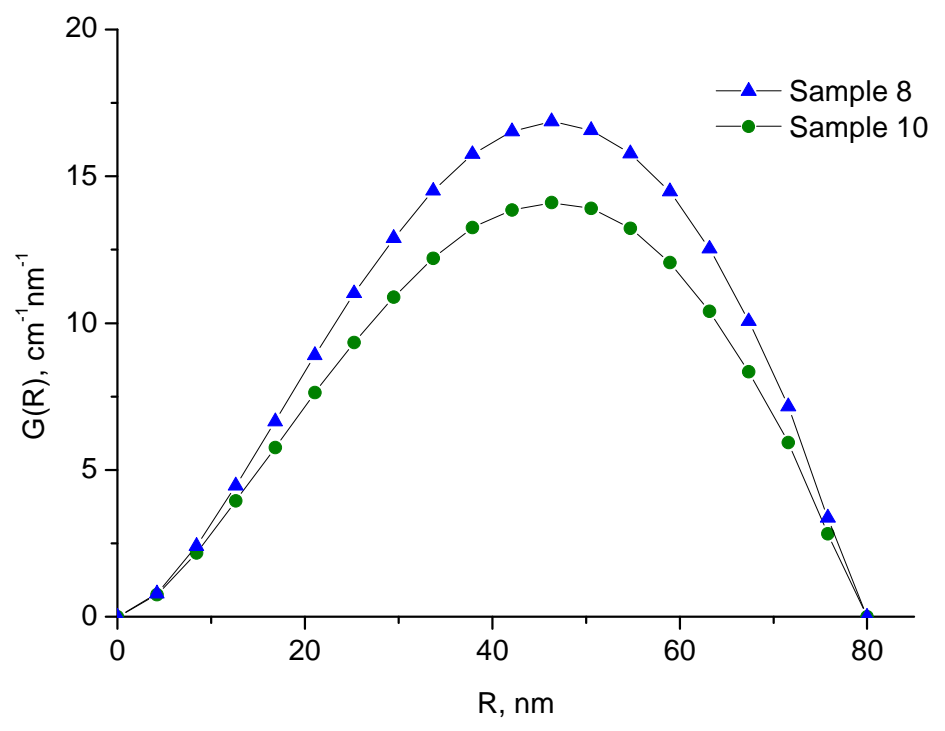

Fig. 2. Distribution functions of scattering objects by distances of samples of cement compositions. Sample $8-$ cement with $\gamma-\mathrm{Al}_{2} \mathrm{O}_{3}$ additive (5\%); Sample 10 - cement with $\alpha-\mathrm{Al}_{2} \mathrm{O}_{3}$ additive (5\%).

\section{V.CONCLUSION}

Nanoadditives influence structural parameters of hydrated portland cement compositions inthe following ways: the distribution of nanoparticles in size, average size of nanoparticles, fractal dimension. Application of filling and modifying nanoadditives makes it possible to purposefully influence on the process of hydration, thereby driving the process of formation of structural parameters of hydrated portland cement compositions and, ultimately, affect the properties of cement stone.

The obtained dependences of structural parameters values of portland cement compositions point to the fact that sludges used as additives, as well as such nanopoders as alpha and gamma of corundum enhance the strength of particles surface area, increase frost resistance, water resistance and corrosion resistance of cement stone, which has a positive effect on the durability of the cement-like construction materials.

\section{REFERENCES}

[1] Bullard J.W., Jennings H.M., Livingston R.A., Nonat A., Scherer G.W., Schweitzer J.S., Scrivener K.L., Thomas J.J. Mechanisms of cement hydration. Cement and Concrete Research, Vol. 41, 2011, pp. 1208-1223.

[2] Nonat A. The structure and stoichiometry of C-S-H. Cement and Concrete Research, Vol. 34, 2004, pp. 1521-1528.

[3] Skinner L.B., Chae S.R., Benmore C.J., Wenk H.R., Monteiro P.J.M. Nanostructure of calcium silicate hydrates in cements. Physical Review Letters, Vol. 104, 195502, 2010, pp. 1-4.

[4] Raki L., Beaudoin J., Alizadeh R., Makar J., Sato T. Cement and concrete nanoscience and nanotechnology. Materials, Vol 3, 2010, pp. 918-942.

[5] Guryanov A.M. Nanoscale investigation by small angle neutron scattering of modified portland cement compositions. Procedia Engineering, Vol. 111, 2015, pp. 283-289.

[6] Guryanov A.M. Investigation of hydrated portland cement structure formation by means of small angle neutron scattering. Procedia Engineering, Vol. 153, 2016, pp. 217-222.
[7] Guryanov A., Korenkova S., Sidorenko Yu. Resceach on the nanolevel influence of surfactants on structure formation of the hydrated portland cement compositions. MATEC Web of Conference, Vol. 86, 04011, 2016, pp. 1-5.

[8] Phair J.W., Schulz J.C., Bertram W.K., Aldridge L.P. Investigation of the microstructure of alkali-activated cements by neutron scattering. Cement and Concrete Research, Vol. 33, 2003, pp. 1811-1824.

[9] Thomas J.J., Allen A.J., Jennings H.M. Density and water content of nanoscale solid $\mathrm{C}-\mathrm{S}-\mathrm{H}$ formed in alkali-activated slag (AAS) paste and implications for chemical shrinkage. Cement and Concrete Research, Vol. 42, 2012, pp. 377-383.

[10] Chiang W.-S., Fratini E., Ridi F., Lim S.-H., Yeh Y.-Q., Baglioni P., Choi S.-M., Jeng U-S., Chen S.-H. Microstructural changes of globules in calcium-silicatehydrate gels with and without additives determined by smallangle neutron and X-ray scattering. Journal of Colloid and Interface Science, Vol. 398, 2013, pp. 67-73.

[11] Trapote-Barreira A., Porcar L., Cama J., Soler J.M., Allen A.J. Structural changes in C-S-H gel during dissolution: Smallangle neutron scattering and Si-NMR characterization. Cement and Concrete Research, Vol. 72, 2015, pp. 76-89.

[12] Korenkova S.F., Sheina T.V. Foundations and the concept of recycling of chemical precipitation in the construction industry. Samara, SGASU, 2004.

[13] Avdeev M.V., Aksenov V.1. Small-angle neutron scattering in structural studies of ferrofluids. Success of physical sciences, Vol. 180, 2010, pp.1009-1034.

[14] Thomas J.J., Chen J.J., Allen A.J., Jennings H.M. Effects of decalcification on the microstructure and surface area of cement and tricalcium silicate pastes. Cement and Concrete Research, Vol. 34, 2004, pp. 2297-2307.

[15] Allen A.J., Thomas J.J., Jennings H.M. Composition and density of nanoscale calcium-silicate-hydrate in cement. Nature Materials, Vol. 6, 2007, pp. 311-316.

[16] Allen A.J., Thomas J.J. Analysis of C-S-H gel and cement paste by small-angle neutron scattering. Cement and Concrete Research, Vol. 37, 2007, pp. 319-324.

[17] Ficker T. Fractal strength of cement gels and universal dimension of fracture surfaces. Theoretical and Applied Fracture Mechanics, Vol. 50, 2008, pp.167-171.

[18] Zeng Q., Luo M., Pang X., L. Li, Li K. Surface fractal dimension: An indicator to characterize the microstructure of cement-based porous materials. Applied Surface Science, Vol. 282, 2013, pp. 302-307. 
[19] Gao Y., Jiang J., Schutter G.D., Ye G., Sun W. Fractal and multifractal analysis on pore structure in cement paste. Construction and Building Materials, Vol. 69, 2014, pp. 253261.

[20] Konarev P.V., Petoukhov M.V., Volkov V.V., Svergun D.I. ATSAS 2.1, a program package for small-angle scattering data analysis. Journal of Applied Crystallography, Vol. 39, 2006, pp. 277-286.
[21] Petoukhov M.V., Franke D., Shkumatov A.V., Tria G., Kikhney A.G., Gajda M., Gorba C., Mertens H.D.T., Konarev P.V., Svergun D.I. New developments in the ATSAS program package for small-angle scattering data analysis. Journal of Applied Crystallography, Vol. 45, 2012, pp. 342-350.

[22] Lebedev V.M., Lebedev V.T., Ivanova I.N., Kolkhidashvili M.R., Orlova D.N. Measuring and analysis system of small angle neutron diffractometer "Membrane-2". Preprint PNPI$2785,2008$. 